\title{
Photophysics of a Water-Soluble Rylene Dye: Comparison with Other Fluorescent Molecules for Biological Applications
}

\author{
Anca Margineanu,,${ }^{\dagger}$ Johan Hofkens, ${ }^{*, \dagger}$ Mircea Cotlet, ${ }^{\dagger}$ Satoshi Habuchi, ${ }^{\dagger}$ Alina Stefan,,${ }^{\dagger}$

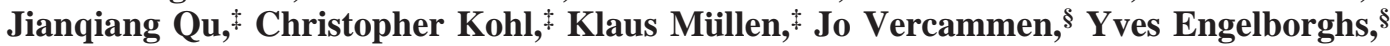 \\ Thomas Gensch," and Frans C. De Schryver*,† \\ Lab. Photochemistry and Spectroscopy, Department Chemistry, KU Leuven, Celestijnenlaan 200F, \\ B-3001, Leuven, Belgium, Max Planck Institut für Polymerforschung, Ackermannweg 10, \\ D-55128, Mainz, Germany, Lab. Biomolecular Dynamics, Department Chemistry, KU Leuven, \\ Celestijnenlaan 200D, B-3001, Leuven, Belgium, and Institut für Biologische Informationverarbeitung 1, \\ Forschungszentrum Jülich, D-52425, Jülich, Germany
}

Received: May 6, 2004

\begin{abstract}
The photophysical properties of a new water-soluble fluorescent dye based on the perylene diimide chromophore are investigated at the ensemble and single molecule level. Water solubility was obtained by attaching hydrophilic substituents in the bay region. The fluorophore has an absorption maximum at $567 \mathrm{~nm}$ and a high quantum yield of fluorescence (0.6). In addition, the two-photon absorption cross section has higher or comparable values with the ones reported in the literature for other water-soluble dyes used in biological studies. The most important finding is its improved photostability in single molecule experiments when compared to other water-soluble dyes. This is demonstrated by the increased observation time of immobilized single molecules, which is almost 10 times higher than for commonly studied fluorophores. A possible reason is the lower intersystem crossing rate constant of perylene diimide in comparison, for example, to rhodamine derivatives. A similar conclusion can be drawn for this chromophore in an aqueous solution, because single molecule measurements using fluorescence correlation spectroscopy demonstrate a very low contribution of the triplet state in the autocorrelation function. The possibility of imaging the new molecule in living cells is demonstrated by one-photon confocal microscopy and by fluorescence lifetime microscopy with two-photon excitation.
\end{abstract}

\section{Introduction}

In recent years, different attempts were made to improve the photophysical/photochemical properties of the fluorescent dyes with possible applications in biology. This is a real necessity today especially as biological measurements are brought down to the single molecule level. ${ }^{1}$ Techniques such as fluorescence correlation spectroscopy, ${ }^{2-5}$ burst-integrated fluorescence lifetime measurements, ${ }^{6}$ or wide-field microscopy ${ }^{7-9}$ are more and more used for single biomolecule detection in vitro and in living cells. General characteristics of a chromophore (e.g., high extinction coefficient, high quantum yield), as well as particularities of biological systems, need to be considered when new fluorescent dyes are proposed. First, a lot of the investigated molecules in biology are water soluble. In contrast, most of the organic fluorescent dyes have a very low solubility or a low quantum yield in water. Second, the low water solubility of organic molecules leads to their aggregation and to modification/ loss of fluorescent properties. Third, the high autofluorescence of living cells when excited between 350 and $450 \mathrm{~nm}$ imposes to design new molecules that absorb visible light above 500

* Corresponding authors. Frans C. De Schryver: tel.: +32-016-327405; fax: +32-016-327989; e-mail: Frans.DeSchryver@chem.kuleuven.ac.be. Johan Hofkens: tel.: +32-016-327804; fax: +32-016-327990; e-mail: Johan.Hofkens@chem.kuleuven.ac.be.

$\dagger$ Lab. Photochemistry and Spectroscopy, KU Leuven.

Max Planck Institut für Polymerforschung.

$\S$ Lab. Biomolecular Dynamics, KU Leuven.

"Institut für Biologische Informationverarbeitung 1. $\mathrm{nm}$ or, better, around $600 \mathrm{~nm}$. This improves the signal/noise ratio especially when single molecule experiments are envisaged. Furthermore, the stability of fluorescent dyes is very important, because the photobleaching will limit the time scale of processes that can be followed.

Different approaches were applied to circumvent some of these problems, such as the use of autofluorescent proteins or, more recently, of water-soluble quantum dots, each of these approaches presenting several advantages, as well as limitations.

In the last 10 years, green fluorescent protein (GFP) was intensively used as an alternative to synthetic dyes. The high quantum yield $(\approx 0.8),{ }^{10}$ the possibility of labeling cellular proteins in situ, the GFP mutants (cyan fluorescent protein, blue fluorescent protein) that can be used to design constructs that undergo fluorescence energy transfer, ${ }^{11}$ and the discovery of the red-emitting protein DsRed ${ }^{12}$ are important reasons that promoted the use of autofluorescent proteins. The main disadvantage when using GFP or its mutants to label other proteins is their relatively high molecular weight $(27000 \mathrm{Da})^{13}$ that can impair the normal dynamics (folding/unfolding) of the studied protein, especially if its molecular weight is not much higher than that of GFP. ${ }^{14}$ To circumvent this disadvantage, a tetracysteine motif that specifically binds biarsenical fluorescent ligands was proposed. ${ }^{15,16}$ Other drawbacks of autofluorescent proteins come from their fast photobleaching and from their complex photophysical properties. Interconversion of the protonated and deprotonated form or structural changes (cis/trans isomerization of the chromophore) are possible in the GFP 
mutants, as well as intersubunit energy transfer in the DsRed. All these lead to multiexponential fluorescence decays and long off times in single molecule experiments. ${ }^{17-20}$

Water-soluble quantum dots ${ }^{21-23}$ are proposed as an alternative because they have a reduced spectral width compared to an organic fluorophore, they are almost 100 times more stable to photobleaching, and the fluorescence intensity of a single particle was equivalent to that of $\approx 20$ rhodamine molecules. ${ }^{24}$ One of their disadvantages could be that after functionalization more than one protein molecule is attached to a single particle (usually 2-5 protein molecules). In addition, their large size ( $\approx 20 \mathrm{~nm}$ ) and the dependence of their photophysical properties on the particle size ${ }^{25}$ can cause problems in biological labeling. ${ }^{26}$

Dendrimers built from amphiphilic units ${ }^{27-29}$ were used for gene transfer, ${ }^{29,30}$ for drug delivery in tumor cells, ${ }^{31,32}$ and for in vivo imaging of tumors with radioactive isotopes. ${ }^{33}$ Because of their size ( $3 \mathrm{~nm}$ or more), the incorporation in living cells occurs probably by endocytosis or receptor-mediated endocytosis when a specific ligand (like folate) is attached. A dendrimer containing three bright fluorescent chromophores such as perylene monoimide, solubilized using nonionic detergents, ${ }^{34}$ can be applied for very sensitive detection (at single molecule level) of cell surface markers by immunolabeling, or of surface receptors, on the condition that ligand-receptor interaction is not significantly perturbed.

The use of porphyrins caged inside dendritic shells as compartmental $\mathrm{pH}$ sensors, ${ }^{35}$ of lanthanide complexes as an alternative to radioactive probes in immunoassay kits, ${ }^{36,37}$ or of aromatic flat fluorophores that replace the base in a DNAlike structure ${ }^{38}$ demonstrates that people keep exploring different approaches to use aromatic chromophores in aqueous environments.

Therefore, classic fluorescent molecules will still be extensively used for measurements in living cells. We focused on rylene dyes (e.g., perylene mono- and diimide, terrylene diimide) because they proved to have remarkable photophysical and photochemical properties both at the ensemble and single molecule level. Their main characteristics are the high quantum yield of fluorescence (almost 1), the high extinction coefficient (38 000-85 000), the excellent stability to photooxidation, and the short-excited-state lifetimes. ${ }^{39,40} \mathrm{Up}$ to now, these properties were investigated in organic solvents or polymer matrixes for dendritic structures containing these chromophores. The watersoluble rylene dye proposed here still retains a high fluorescence quantum yield in water and excellent photophysical properties in single molecule experiments. The long survival time of immobilized molecules, as well as the high number of counts of freely diffusing molecules in fluorescence correlation spectroscopy experiments, can make this dye the molecule of choice over other water-soluble fluorophores.

\section{Experimental Section}

The structure of the fluorescent molecule containing the perylene diimide chromophore is presented in Figure 1.

The synthesis of this dye was published elsewhere. ${ }^{41}$

Milli-Q water (18 M $\Omega$ resistance) was used for all experiments. All solvents were spectroscopic grade (Sigma). Phosphate buffer saline (PBS) with $\mathrm{pH} 7.4$ was purchased from Sigma and reconstituted with Milli-Q water. Poly(vinyl alcohol) (PVA) was obtained from Clariant (Switzerland) and prepared as a $1 \%$ w/w solution in PBS.

Steady-state ensemble measurements were performed with a Perkin-Elmer Lambda 40 spectrophotometer (Wellesley, MA) for absorption spectra and with a Spex Fluorolog 3-22 fluo-

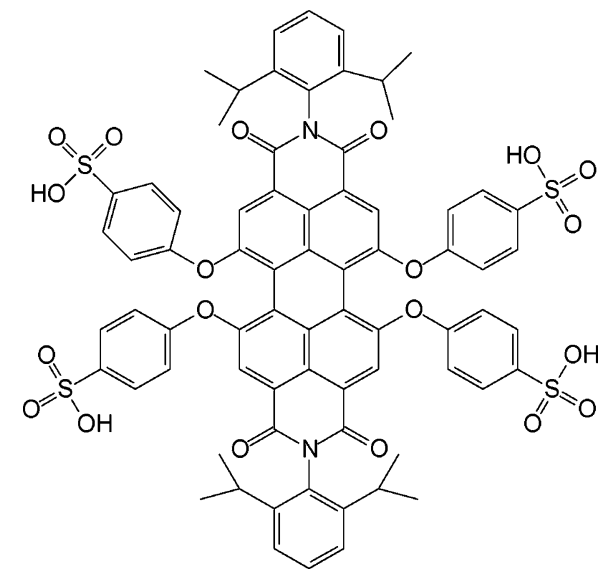

Figure 1. Structure of the investigated water-soluble perylene diimide (compound 1).

rimeter (Jobin Yvon-Spex Instruments S. A., Inc., Edison, NJ) for fluorescence spectra. Emission spectra were corrected according to standard procedures. ${ }^{42}$

Excitation light for the determination of the two-photon absorption cross section was obtained from a system using a diode pumped laser (Millenia, Spectra Physics) directed into a mode-locked Ti:sapphire (Tsunami 3950D, Spectra Physics) by tuning the whole available wavelength range $(840-970 \mathrm{~nm})$. The generated pulse width is less than $2 \mathrm{ps}$ and the repetition rate is $82 \mathrm{MHz}$. The polarized light was focused through a Nikon objective lens $(20 \times, 0.35 \mathrm{NA})$ into the cuvette. Detection was realized in a $90^{\circ}$ geometry using a monochromator (9030DS, Sciencetech), which wavelength was selected to correspond to the maximum emission for each chromophore, and a microchannel plate (R3809U, Hamamatsu) connected to a timecorrelated single photon counting personal computer TCSPC PC card (SPC 630, Becker \& Hickl GmbH, Germany). Water solutions containing $8.33 \times 10^{-6} \mathrm{M}$ rhodamine $\mathrm{B}$ (Radiant Dyes Chemie) and $4.33 \times 10^{-5} \mathrm{M}$ compound 1 were used. Calculation of the two-photon absorption cross section for compound 1 was done using rhodamine $\mathrm{B}$ as a reference, considering the formula ${ }^{43}$

$$
\frac{\langle F(t)\rangle_{\mathrm{R}}}{\langle F(t)\rangle_{\mathrm{S}}}=\frac{\Phi_{\mathrm{R}} C_{\mathrm{R}} \delta_{2 \mathrm{p}-\mathrm{R}}}{\Phi_{\mathrm{S}} C_{\mathrm{S}} \delta_{2 \mathrm{p}-\mathrm{S}}}
$$

where $F(t), \Phi, C$, and $\delta_{2 \mathrm{P}}$ are, respectively, the fluorescence intensity, the fluorescence quantum yield, the concentration, and the two-photon absorption cross section. $\mathrm{R}$ and $\mathrm{S}$ stand for the reference and sample.

The single photon timing setup is described in detail elsewhere. ${ }^{44,45}$ In brief, the output of a mode-locked Ti:sapphire laser (Tsunami 3950D, Spectra Physics) pumped by an argon ion laser (Beamlock 2080A-12, Spectra Physics) was directed into a frequency doubled optical parametric oscillator to deliver the 543-nm wavelength used for excitation. Emission light, passed through a sheet polarizer set to the magic angle $\left(54.7^{\circ}\right)$, is focused on a monochromator (9030DS, Sciencetech) to obtain spectral separation and is detected with a microchannel plate (R3809U, Hamamatsu). Acquisition was done using a TCSPC PC card (SPC 630, Becker \& Hickl GmbH, Germany). The experimental instrument response function was about 50 ps. Decays were collected in 4096 channels with at least 10000 counts in the maximum. Data from single photon timing were analyzed using a homemade program based on a Marquardt algorithm, by convoluting the experimental instrument response function with exponential model functions. The fitting was 
judged by the value of the reduced chi-square parameter (maximum acceptable value is considered 1.2) and also by the appearance of the residuals.

Fluorescence correlation spectroscopy (FCS) measurements were carried out with a commercially available Confocor 2 system (Zeiss). The 543-nm excitation wavelength was provided by a $\mathrm{He}-\mathrm{Ne}$ laser (Lasos, LGK $7786 \mathrm{P}$ ) with maximum output power of $35 \mathrm{~kW} / \mathrm{cm}^{2}$ at the sample and was directed to the sample using a water immersion objective lens $(40 \times, 1.2 \mathrm{NA})$. Fluorescence was separated through a 543-nm dichroic mirror and a 560-nm long pass filter. Aqueous solutions containing $10^{-9} \mathrm{M}$ rhodamine $\mathrm{B}$, tetramethyl rhodamine isothiocyanate (TRITC) (Sigma), or compound 1 were placed in a Nunc chambered coverglass (eight wells). Calibration of the system was done with rhodamine 6G (Molecular Probes). Data were analyzed using a fitting function taking into account contributions of the intersystem crossing (triplet) and the diffusion ${ }^{46}$ in the commercially available Origin program:

$$
G(\tau)=1+\frac{1}{N}\left(1-T+T \cdot e^{\tau / \tau_{\text {triplet }}}\right)\left(\frac{1}{1+\frac{\tau}{\tau_{\mathrm{D}}}}\right) \frac{1}{\left(1+\left(\frac{r_{0}}{z}\right)^{2} \frac{\tau}{\tau_{D}}\right)^{1 / 2}}
$$

where $G(\tau)=$ autocorrelation function, $N=$ number of molecules in the laser focus, $T=$ triplet fraction, $\tau_{\text {triplet }}=$ lifetime of the triplet state, $\tau_{\mathrm{D}}=$ diffusion time, $r_{0}, z=$ parameters of the laser focus.

The setup for single molecule measurements (for detailed description see ref 47) uses the same system for excitation as the single photon timing, but the light is directed on the back aperture of an Olympus IX 70 inverted microscope. An oil immersion lens (Olympus 100×; 1.4 NA) was used. Samples were mounted on a scanning stage (Physics Instruments, Waldbrown, Germany). Fluorescence is collected by the same lens, then passed through a dichroic mirror (Chroma Technology, Brattleboro, NY) and a notch filter (Kaiser Optical Systems, Ann Arbor, MI), and focused on a $50-\mu \mathrm{m}$ pinhole. A $50 \%-$ $50 \%$ beam splitter was used to direct the light on an avalanche photodiode APD (SPCM 15, EG \& G, Quebec) and on a polychromator (Acton SP 150) coupled to a nitrogen-cooled charge-coupled device camera (Princeton Instruments). In some measurements, all emitted light was collected by the APD. Samples were prepared as a thin polymer film (PVA in PBS) containing $\approx 10^{-9} \mathrm{M}$ fluorescent molecules, deposited on the surface of a coverslip by spin-coating (3000 rpm for $1 \mathrm{~min}$ ). Coverslips were cleaned by sonication in acetone, $\mathrm{NaOH}$, and Milli-Q water and exposure to UV/ozone. Laser focus was parked on individual fluorescent molecules and the signal detected by the APD was recorded with a TCSPC PC card (SPC 630, Picoquant $\mathrm{GmbH}$ ) using the FIFO mode (first in, first out). This allows the detection of the time interval of each photon with respect to the excitation pulse and also the time lag with respect to the previous detected photon. The stored data are used to reconstruct the fluorescence intensity trace (transient) with a time resolution of $50 \mathrm{~ns}$, as well as to generate timeresolved decays along the transient. Decays stored in 256 channels with 2000 photons/decay were obtained by sliding scale analysis for each individual molecule. For single molecule experiments, decays were generated and analyzed by using a similar homemade program as for single photon timing measurements, with fitting based on the maximum likelihood estimator. ${ }^{48}$ For the determination of the intersystem crossing rate of compound 1 , the 568-nm continuous wavelength excitation from an $\mathrm{Ar}-\mathrm{Kr}$ laser (Stabilite 2018-RM, Spectra Physics) was used.
Confocal laser scanning microscopy images of cells were acquired with an IX70 Olympus microscope and the Fluoview FV500 program (Olympus). Continuous 543-nm excitation wavelength from a HeNe laser (05-LGP-193, Melles Griot) was directed on the sample through an oil immersion objective lens $(60 \times, 1.4 \mathrm{NA})$, fluorescence being separated through a 488/ 543-nm dichroic mirror and a long pass filter $560 \mathrm{~nm}$ (Chroma Technology). Chinese hamster ovary (CHO) cells were grown on coverslips covered with polylysine $(0.01 \%$ water solution; Sigma). Loading of compound $1(5 \mu \mathrm{M})$ was done in culture medium without phenol red (Opti-MEM, Gibco) supplemented with $2 \%$ bovine serum albumin (Sigma). After $2 \mathrm{~h}$, cells were washed three times with PBS buffer and images were taken.

Two-photon lifetime imaging in living cells was obtained using as an excitation source a pulsed Ti-sapphire laser (150 fs pulse width, $76 \mathrm{MHz}$ frequency, Mira 900-F, Coherent) pumped by a diode laser pumped, frequency doubled $\mathrm{Nd}: \mathrm{YVO}_{4}(\mathrm{Nd}$ : Vanadate) laser (Verdi V-5, Coherent, $5 \mathrm{~W}$ output at $532 \mathrm{~nm}$ ). The excitation wavelength was $850 \mathrm{~nm}(5-20 \mathrm{~mW}$ at the sample). Fluorescence is detected in an upright microscope BX50WI (Olympus) using a LUMIPlanFL/IR $(60 \times, 0.9$ NA) water immersion objective lens. The emitted light is separated from the excitation light using a near-infrared dichroic mirror and a broad-band visible interference filter with high blockage in the near-infrared spectral region. Fluorescence images are produced by scanning the focused excitation light in the sample plane with a galvanic mirror based beam scanner (Yanus, TILL Photonics). Emitted light is detected by a photomultiplier working in single photon counting mode (H5773P-01, Hamamat$\mathrm{su})$. The fluorescence lifetime is determined from the decay curves obtained by registration and histograming of the time delay of the fluorescence photons relative to the excitation pulse in TCSPC mode with a TCSPC card with routing option to assign the detected photons to the respective points in the sample plane (SPC730, Becker \& Hickl). Acquisition and processing of images were done with the commercially available computer programs SPC 7.22 and SPCImage 2.5 (Becker \& Hickl). HEK293 cells were incubated with compound $1(1 \mu \mathrm{M})$ for 4 $\mathrm{h}$ in a physiological buffer $(120 \mathrm{mM} \mathrm{NaCl}, 5 \mathrm{mM} \mathrm{KCl}, 2 \mathrm{mM}$ $\mathrm{MgCl}_{2}, 2 \mathrm{mM} \mathrm{CaCl}$, $10 \mathrm{mM}$ glucose, 10 mM HEPES, pH 7.4) supplemented with $15 \mathrm{mg} / \mathrm{mL}$ BSA. Images were taken after washing with the physiological buffer free of compound 1 .

\section{Results and Discussions}

In this study, we evaluate a new water-soluble fluorescent molecule based on the perylene diimide (PDI) chromophore. Its molecular weight is relatively small $(\approx 1400)$, which makes it a good candidate for labeling proteins or other biologically active molecules, avoiding the limitations of the large size autofluorescent proteins, quantum dots, or dendrimers.

Steady-State Measurements. The absorption spectrum of compound 1 in water (Figure 2) has a similar shape as the spectrum of other PDIs in organic solvents. ${ }^{49,50}$ Two electronic transitions are visible in the absorption spectrum of this chromophore. ${ }^{51}$ The $\mathrm{S}_{0}-\mathrm{S}_{1}$ transition (along the long axis) is situated between 480 and $625 \mathrm{~nm}$, and the $S_{0}-S_{2}$ transition (along the short axis) appears as a second peak between 400 and $480 \mathrm{~nm}$. The position of the $S_{0}-S_{1}$ absorption maximum of the water-soluble PDI is not significantly changed compared to PDI in organic solvents, but the $\mathrm{S}_{0}-\mathrm{S}_{2}$ absorption peak is bathochromically shifted by $\approx 700 \mathrm{~cm}^{-1}$ (from 440 to $454 \mathrm{~nm}$ ). The maximum of the emission spectrum (Figure 2), taken with an excitation wavelength of $543 \mathrm{~nm}$, is also bathochromically shifted by $\approx 670 \mathrm{~cm}^{-1}$ (from 600 to $625 \mathrm{~nm}$ ) for the watersoluble derivative. 


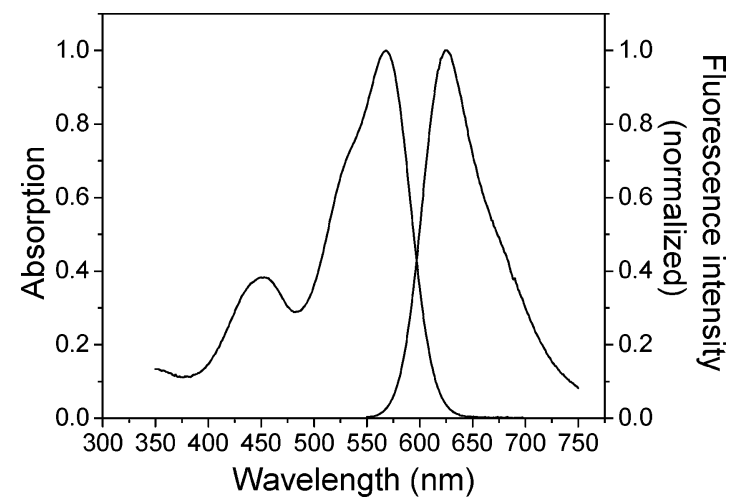

Figure 2. Normalized absorption and fluorescence emission spectra for compound 1 .

Therefore, the 543- or 568-nm wavelengths can be used to excite this dye loaded into cells, obtaining a good signal/noise ratio due to the reduced autofluorescence in the green region of the visible spectrum.

In water, the molar extinction coefficient of compound 1 is approximately $30000 \mathrm{M}^{-1} \mathrm{~cm}^{-1}$, while the quantum yield of fluorescence $\left(\Phi_{\mathrm{f}}\right)$ equals 0.6 . The $\Phi_{\mathrm{f}}$ value is higher than that reported for quantum dots $(0.35-0.5)^{24}$ or for cyanine dyes $(0.2),{ }^{52}$ but lower than for GFP or rhodamines $(0.8-0.9){ }^{10,53}$ Anyway, a $\Phi_{\mathrm{f}}$ value of 0.6 is high enough for single molecule applications.

Two-Photon Absorpton Cross Section. The molecule was tested for possible two-photon applications, especially since these experiments are advantageously used in living cell imaging. In Figure 3A, the fluorescence intensity shows a linear dependence when plotted as a function of excitation intensity at $840 \mathrm{~nm}$ (in a double logarithmic scale), with a slope of 1.9, indicating a two-photon absorption process. The two-photon absorption cross section for this dye was determined using rhodamine $\mathrm{B}$ as a reference ${ }^{43,54,55}$ and varied between 10 and $50 \mathrm{GM}\left(1 \mathrm{GM}=10^{-50} \mathrm{~cm}^{4} \mathrm{~s}\right)$ in the scanned range $(840-970$ $\mathrm{nm}$ ) (Figure 3B). Values up to $10 \mathrm{GM}$ were reported for many fluorophores commonly used in biology, and only few of them have two-photon absorption cross sections between 10 and 100 GM. ${ }^{55}$ The higher value obtained for compound 1 in this spectral region is probably related to the $S_{0}-S_{2}$ transition.

These data indicate that the compound can be efficiently excited with wavelengths corresponding to the $S_{0}-S_{1}$ and $S_{0}-$ $\mathrm{S}_{2}$ transitions.

Ensemble Time-Resolved Measurements. The fluorescence decay recorded at the emission maximum was fitted as a monoexponential function, with a lifetime of $4.9 \mathrm{~ns}$, which is approximately $1 \mathrm{~ns}$ less than for PDI-containing dendrimers in organic solvents. ${ }^{49}$ Considering $\Phi_{\mathrm{f}}=k_{\mathrm{f}} /\left(k_{\mathrm{f}}+k_{\mathrm{nr}}\right)$ (where $k_{\mathrm{f}}=$ fluorescence rate constant, $k_{\mathrm{nr}}=$ rate constant for nonradiative processes) and $\Phi_{\mathrm{f}} \approx 1$ for PDI in organic solvents, ${ }^{50}$ than $k_{\mathrm{nr}}$ is almost 0 . In these conditions, the fluorescence lifetime $\tau_{\mathrm{f}}$ equals $1 / k_{\mathrm{f}}$, and $k_{\mathrm{f}} \approx 1.6 \times 10^{8} \mathrm{~s}^{-1}$ assuming $\tau_{\mathrm{f}} \approx 6$ ns for PDI. ${ }^{49}$ For the water-soluble PDI derivative, the quantum yield equals 0.6 , meaning that $k_{\mathrm{nr}}$ is no longer negligible. With the previous assumptions, the calculated $k_{\mathrm{nr}}$ is $\approx 6.4 \times 10^{7} \mathrm{~s}^{-1}$. Consequently, a reduction of the $\tau_{\mathrm{f}}$ value is expected in water: $\tau_{\mathrm{f}}=1 /\left(k_{\mathrm{f}}+\right.$ $\left.k_{\mathrm{nr}}\right) \approx 4.5 \mathrm{~ns}$, which is in good agreement with the experimental data. One possible explanation for the increased nonradiative rate constant in water could be the induced vibrational relaxation through hydrogen bonding between water molecules and the polar groups of the chromophore.

Single Molecule Measurements. A. Single Molecule Measurements in Solution. Fluorescence correlation spectroscopy
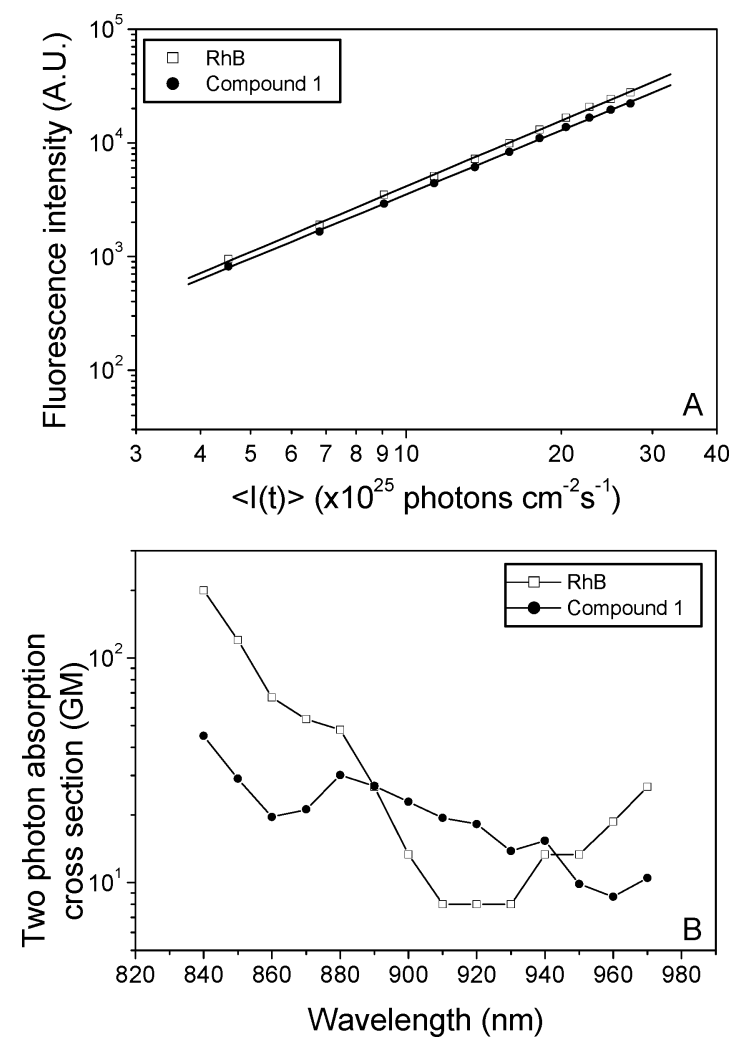

Figure 3. (A) Linear dependence (double logarithmic scale) of fluorescence intensity and excitation intensity value at $840 \mathrm{~nm}$. The slope for both dyes is $\approx 1.9$, indicating a two-photon absorption process. (B) The two-photon absorption cross section for rhodamine $\mathrm{B}^{43,54,55}$ ( $\square$ ) and for compound 1 ( ) calculated using rhodamine B as a reference.

in a $10^{-9} \mathrm{M}$ water solution was performed to test the possibility of using compound 1 for single molecule measurements.

As expected from the higher molecular weight of compound $1(\approx 1400)$ compared to that of rhodamine dyes $(400-500)$, its diffusion time of $50 \mu \mathrm{s}$ is larger than that for rhodamines (30 $\mu \mathrm{s})$. It is interesting to observe that even though the fluorescence quantum yield for compound 1 is less than that of rhodamines in water, the number of counts per molecule is comparable (Figure 4D). Furthermore, a plateau is reached for the number of counts for TRITC (less evident for rhodamine B), but not for compound 1 . This finding can be related to the contribution of the triplet state in the autocorrelation curve (Figure 4E). Even for the highest power we used, the triplet fraction remains lower than $10 \%$ in compound 1 , while for rhodamines it increases to more than $30 \%$ for similar excitation power. This is also visible in the shape of the autocorrelation curve (Figure 4A). Indeed, fitting the autocorrelation curves with only one component representing the diffusion gives only a minimum deviation from the experimental data in compound 1 , but not for rhodamine $\mathrm{B}$ (Figure 4B, C). The low contribution of the triplet is an indication that the triplet state is less frequently populated in compound 1 , which can be a reason for a similar number of counts per molecule as rhodamine B and for its improved photostability (vide infra). The triplet lifetime of the watersoluble PDI is comparable to that of rhodamine B and TRITC $(1.5-2 \mu \mathrm{s})$. The photobleaching of molecules in the laser focus (observed as an apparent reduction in the diffusion time ${ }^{57}$ ) could not be achieved with the maximum power we used $(35 \mathrm{~kW} /$ $\left.\mathrm{cm}^{2}\right)$.

B. Single Molecule Measurements in a Polymer Matrix (PVA). a. Photostability. Fluorescence intensity traces and decays were 

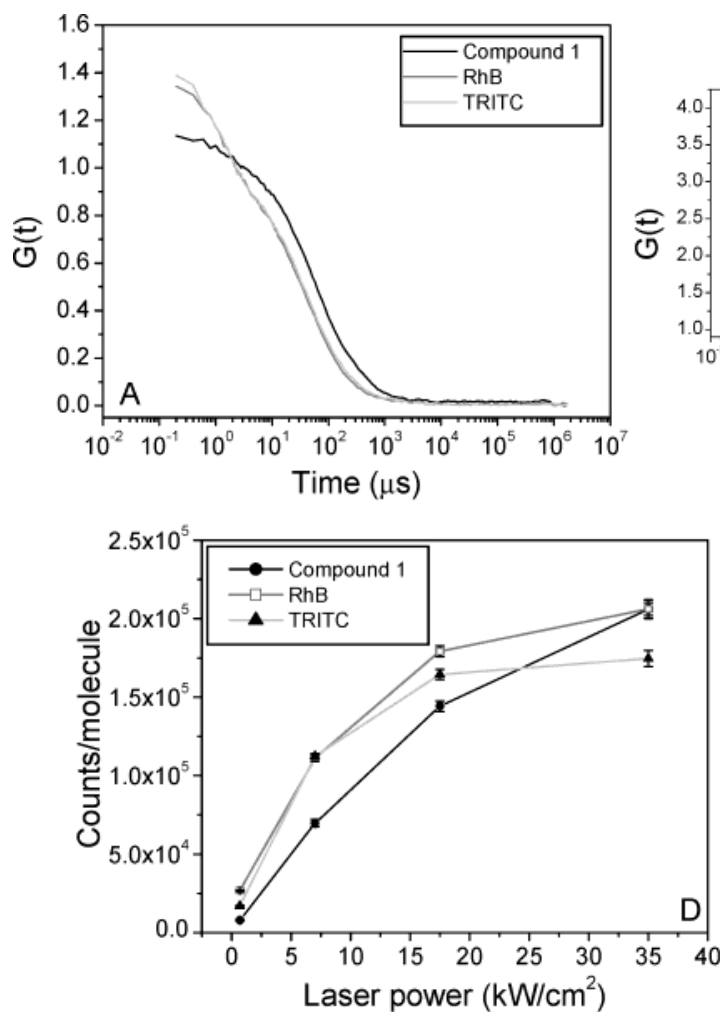
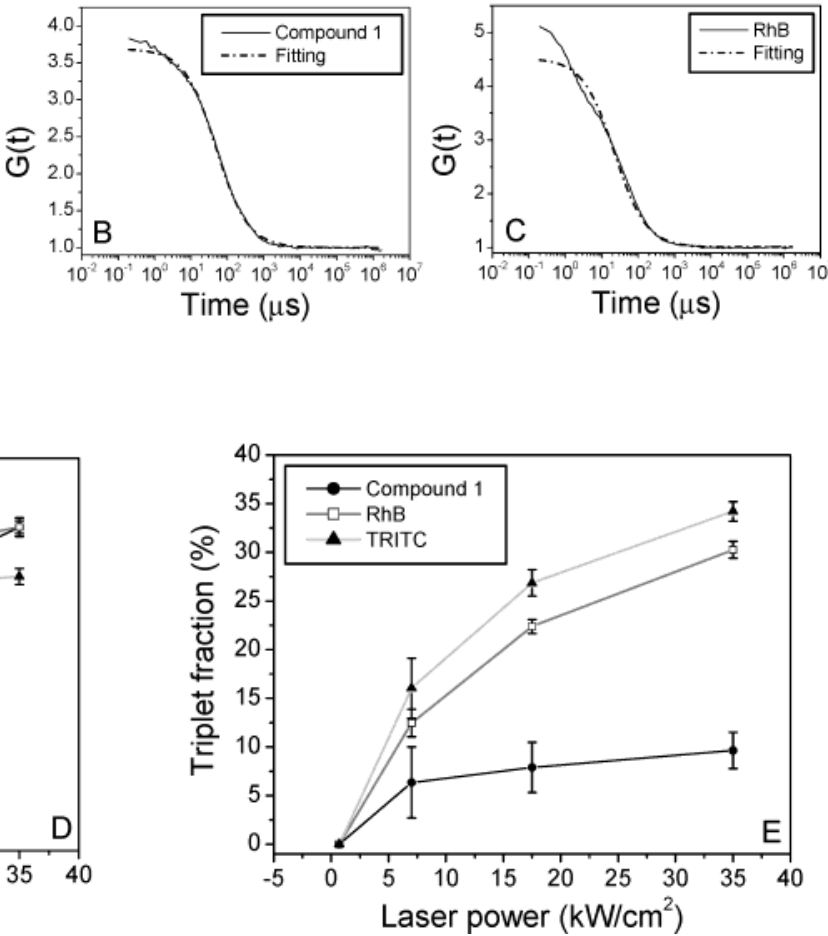

Figure 4. (A) Typical autocorrelation curves obtained with the maximum excitation power $\left(35 \mathrm{~kW} / \mathrm{cm}^{2}\right)$ for compound 1 , rhodamine $\mathrm{B}$, and TRITC. Normalization was done by multiplying $G(\mathrm{t})$ with the average number of fluorescent molecules in the focal area. ${ }^{56}$ (B) Fitting the experimental autocorrelation curve with only one component representing the diffusion gives only a minimal deviation in compound 1, indicating a very low contribution of the triplet. (C) Fitting the experimental autocorrelation curve with only one component representing the diffusion gives an important deviation in rhodamine B; the triplet contribution is significant in this case. (D-E) Parameters determined in FCS experiments using different excitation powers: number of counts per molecule (D) and triplet fraction in the autocorrelation curve (E). The standard deviation is calculated for 10 measurements.

recorded with pulsed excitation light for 74 molecules. Spectra were taken for 29 of these molecules. The lifetime of a single compound 1 molecule, as well as the value of the maximum wavelength of the emission spectrum, remains very much constant until photobleaching occurs. An image of single molecules of compound 1 in PVA matrix $(10 \times 10 \mu \mathrm{m})$ and typical photophysical characteristics of compound 1 molecules are presented below (Figure 5). As can be observed, because of a change in the microenvironment sensed by the molecules, lifetimes longer than in solution $(5 \mathrm{~ns})$ are detected.

Figure 6 represents the histograms for the duration of transients and of the total number of detected photons for all measured molecules. The mean survival time for these molecules is estimated to be $94 \mathrm{~s}$, the mean number of total detected photons being around 750000 .

The data obtained from single molecule experiments point to the fact that this fluorophore has an excellent stability to photobleaching. One of the disadvantages related to the study of single biomolecules is the short observation time (usually between 10 and $20 \mathrm{~s}$ ) due to the photobleaching of the chromophores used as labels. These times are too short to follow, for instance, the folding of a single protein over the full range of relevant time scales. ${ }^{58}$ Measurements of compound 1 show that these molecules can provide longer observation times than other available water-soluble chromophores even without the use of oxygen scavengers, ${ }^{59}$ which cannot be applied in all experiments because of possible interference with cellular processes.

Different mechanisms were proposed for the photobleaching process. Organic molecules in the long-lived triplet state can react with the ground-state molecular oxygen in a triplet-triplet annihilation process, resulting in the photooxidation of the molecule by the excited singlet oxygen produced in the reaction. This scheme is important especially in solution. ${ }^{60} \mathrm{~A}$ second mechanism involving the triplet state is the absorption of an additional photon to a second excited metastable state with a nonradiative decaying pathway or a high reactivity. ${ }^{60-62}$ This mechanism is involved when pulsed excitation power is used and especially in two-photon spectroscopy/microscopy. Conventionally, the total number of photons emitted per second by a fluorescent molecule can be calculated using its photophysical parameters such as the fluorescence quantum yield, the singlet excited state lifetime, the intersystem crossing rate, and the triplet lifetime. This can lead to the idea that if the molecule emits a finite number of photons, intense excitation will produce high count rates, but fast photobleaching, and vice versa. Single molecule measurements revealed that in fact the excitation intensity can have a much stronger effect: high excitation intensity yields relatively few photons, while very low intensity yields several orders of magnitude more detected photons. ${ }^{62}$

For single molecules, the photobleaching rate is given by the inverse of the single molecule survival time, and an exponential distribution should be found if the process occurs from the triplet state. ${ }^{61,63}$ This is indeed the case for the compound 1 molecules, for which an average survival time of $94 \mathrm{~s}$ (almost 10 times higher than for rhodamine molecules ${ }^{24}$ ) and an average number of 750000 detected photons were determined in PVA matrix, using an excitation power of $1.4 \mathrm{~kW} / \mathrm{cm}^{2}$. Almost half of the molecules show a survival time longer than $100 \mathrm{~s}$ (up to 1200 s) and more than $10^{6}$ detected photons (up to $8 \times 10^{6}$ ). It is true that the polymer matrix used slows down the oxygen diffusion compared to an aqueous solution, but even in these 

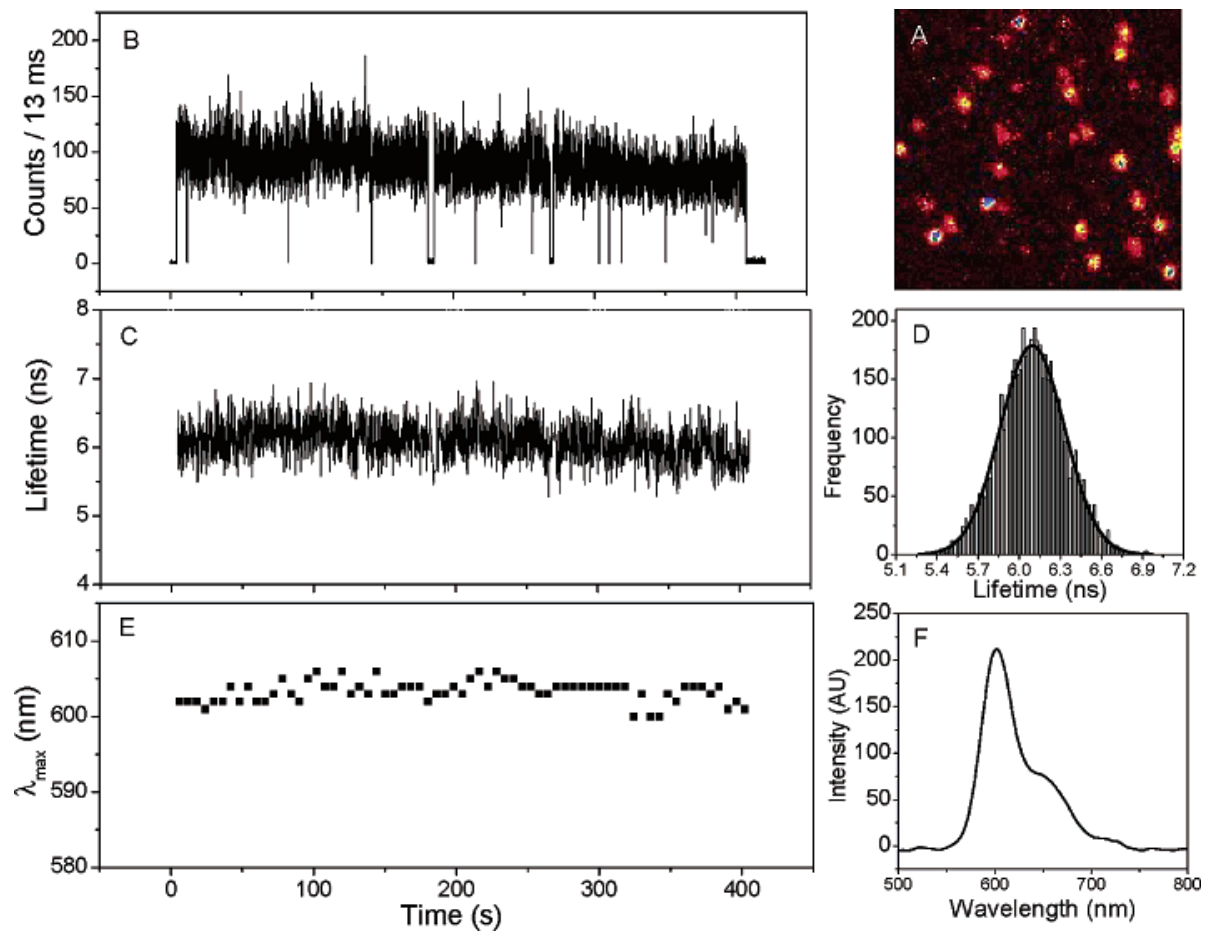

Figure 5. (A) An image of single molecules of compound 1 in PVA matrix $(10 \times 10 \mu \mathrm{m})$. (B-F) Single molecule of compound 1: (B) Fluorescence intensity as a function of time (transient) shows a very long survival time $(\approx 400 \mathrm{~s}) ;(\mathrm{C})$ lifetime trajectory remains relatively constant around an average value; (D) the distribution of lifetimes from the lifetime trajectory has a maximum around $6.1 \mathrm{~ns}$; (E) the time evolution of spectral maxima shows small variations between 600 and $605 \mathrm{~nm}$; (F) typical single molecule spectrum.
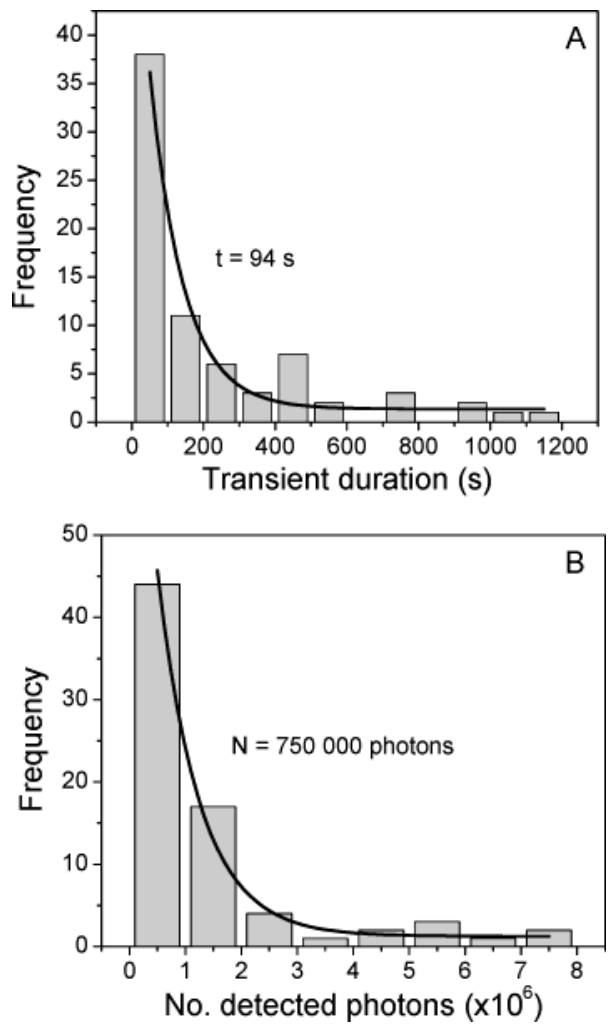

Figure 6. Histograms representing the distributions of the duration of transients (A) and the number of detected photons (B) for compound 1 molecules. Both distributions were fitted as monoexponential functions.

conditions the two parameters are much higher than for the widely used chromophores such as rhodamines, fluorescein, $\mathrm{Cy} 3$, and Cy5. In comparable experiments, rhodamine 6G molecules entrapped in a trehalose matrix present an average survival time less than $20 \mathrm{~s}$, and an average number of detected photons around 500000 , for excitation powers $0.4-1.4 \mathrm{~kW} /$ $\mathrm{cm}^{2}{ }^{64}$ TRITC molecules in PVA have an average survival time of $11 \mathrm{~s}$ at $4.5 \mathrm{~kW} / \mathrm{cm}^{2} 65$ and nile red in PVA matrix emits for approximately $12 \mathrm{~s}$ at $1 \mathrm{~kW} / \mathrm{cm}^{2}{ }^{66}$ Zondervan et al. ${ }^{67}$ report an average time before photobleaching for rhodamine $6 \mathrm{G}$ molecules in PVA of $11 \mathrm{~s}$ in air and $22 \mathrm{~s}$ in inert atmosphere at $1.5 \mathrm{~kW} /$ $\mathrm{cm}^{2}$. An increase in the survival time to $1000 \mathrm{~s}$ can be obtained only for rhodamine $6 \mathrm{G}$ molecules in polymethyl methacrylate matrix under vacuum, excited with $0.7 \mathrm{~kW} / \mathrm{cm}^{2} .^{62}$ Using a laser power of $500 \mathrm{~W} / \mathrm{cm}^{2}$, the total number of detected photons from molecules on the glass surface were 80000 for JA242 (an oxazine derivative) and JF9 (a rhodamine derivative) and 30000 for Cy5. ${ }^{68}$ Almost $90 \%$ of the sulforhodamine 101 molecules in polymethyl methacrylate matrix emit only 560000 photons for half of the excitation power we used. ${ }^{60}$ For $1.4 \mathrm{~kW} / \mathrm{cm}^{2}$ excitation power, but on a glass surface, the average number of photons emitted and detected from rhodamine B molecules decreases to $92000 .{ }^{60}$ When EGFP molecules are embedded in a PVA matrix, excitation with $350 \mathrm{~W} / \mathrm{cm}^{2}$ can lead to a high number of counts (125-750 counts per $5 \mathrm{~ms}$ ), but during observation periods of $100 \mathrm{~s}$ the autofluorescent protein emits only a few bursts $(0.5-2 \mathrm{~s}$ duration) separated by long dark periods (seconds to several tens of seconds). ${ }^{19}$ In the same conditions, DsRed molecules emit for at least $10 \mathrm{~s} .{ }^{19} \mathrm{In}$ other cases, like for autofluorescent proteins trapped in agarose gel, the comparison is hard to be done because a higher excitation power was necessary to obtain a good signal/noise ratio (several $\mathrm{kW} / \mathrm{cm}^{2}$ ); under this condition, DsRed photobleaches after a few seconds and emits approximately 5000 photons per second, while EGFP can survive only a few hundreds milliseconds. ${ }^{69}$ A summary of these data is presented in Table 1 .

b. Intersystem Crossing Rate Constant. Usually, the dark states visible on the fluorescence intensity traces in single 
TABLE 1: Survival Time and Number of Detected Photons for the Fluorescent Dyes Commonly Used in Biology ${ }^{a}$

\begin{tabular}{|c|c|c|c|c|c|}
\hline dye & survival time & $\begin{array}{l}\text { no. detected } \\
\text { photons }\end{array}$ & environment & $\begin{array}{l}\text { excitation } \\
\text { power }\end{array}$ & ref \\
\hline$\underset{1}{\text { compound }}$ & $94 \mathrm{~s}$ & 750000 & PVA & $1.4 \mathrm{~kW} / \mathrm{cm}^{2}$ & \\
\hline \multirow[t]{3}{*}{ Rh6G } & $15 \mathrm{~s}$ & 500000 & trehalose & $\begin{array}{l}0.4-1.4 \\
\mathrm{~kW} / \mathrm{cm}^{2}\end{array}$ & 64 \\
\hline & $\begin{array}{l}11 \mathrm{~s}(\text { air }) \\
22 \mathrm{~s}\left(\mathrm{~N}_{2}\right)\end{array}$ & & PVA & $1.5 \mathrm{~kW} / \mathrm{cm}^{2}$ & 67 \\
\hline & $1000 \mathrm{~s}$ & & $\begin{array}{l}\text { PMMA vacuum } \\
\text { glass }\end{array}$ & $0.7 \mathrm{~kW} / \mathrm{cm}^{2}$ & $\begin{array}{l}62 \\
60\end{array}$ \\
\hline $\begin{array}{l}\text { RhB } \\
\text { SRh } 101\end{array}$ & & $\begin{array}{l}92000 \\
560000\end{array}$ & $\begin{array}{l}\text { glass surface } \\
\text { PMMA }\end{array}$ & $\begin{array}{l}1.4 \mathrm{KW} / \mathrm{cm}^{2} \\
0.7 \mathrm{~kW} / \mathrm{cm}^{2}\end{array}$ & $\begin{array}{l}60 \\
60\end{array}$ \\
\hline TRITC & $11 \mathrm{~s}$ & & PVA & $4.5 \mathrm{~kW} / \mathrm{cm}^{2}$ & 65 \\
\hline Nile red & $12 \mathrm{~s}$ & & PVA & $1 \mathrm{~kW} / \mathrm{cm}^{2}$ & 66 \\
\hline JA242 & & 80000 & glass surface & $500 \mathrm{~W} / \mathrm{cm}^{2}$ & 68 \\
\hline Су5 & & 30000 & glass surface & $500 \mathrm{~W} / \mathrm{cm}^{2}$ & 68 \\
\hline JF9 & & 80000 & glass surface & $500 \mathrm{~W} / \mathrm{cm}^{2}$ & 68 \\
\hline DsRed & few $s$ & 5000 per s & agarose gel & $\begin{array}{l}\text { several } \\
\mathrm{kW} / \mathrm{cm}^{2}\end{array}$ & 69 \\
\hline \multirow[t]{2}{*}{ EGFP } & $\begin{array}{l}10 \mathrm{~s} \\
\text { few hundreds } \\
\mathrm{ms}\end{array}$ & & $\begin{array}{l}\text { PVA } \\
\text { agarose gel }\end{array}$ & $\begin{array}{l}350 \mathrm{~W} / \mathrm{cm}^{2} \\
\text { several } \\
\mathrm{kW} / \mathrm{cm}^{2}\end{array}$ & $\begin{array}{l}19 \\
69\end{array}$ \\
\hline & $\begin{array}{l}\text { few bursts } \\
\quad(0.5-2 \mathrm{~s})\end{array}$ & $\begin{array}{l}25000- \\
150000 \\
\text { per s }\end{array}$ & PVA & $350 \mathrm{~W} / \mathrm{cm}^{2}$ & 19 \\
\hline $\begin{array}{c}\text { quantum } \\
\text { dots }\end{array}$ & $\begin{array}{l}100 \text { times more } \\
\text { than } \mathrm{Rh} \\
(>1000 \mathrm{~s})\end{array}$ & $\begin{array}{l}\approx 20 \mathrm{Rh} \\
\quad \text { molecules }\end{array}$ & & & 24 \\
\hline
\end{tabular}

${ }^{a}$ Rh6G, rhodamine 6G; RhB, rhodamine B; SRh 101, sulforhodamine 101; TRITC, tetramethyl rhodamine isothiocyanate; JA242, oxazine derivative; JF9, rhodamine derivative; EGFP, enhanced green fluorescent protein; PVA, poly(vinyl alcohol); PMMA, polymethyl methacrylate. Excitation powers reported in the cited papers were converted in $\mathrm{kW} / \mathrm{cm}^{2}$ considering the diameter of the laser focus $\approx 300$ nm.
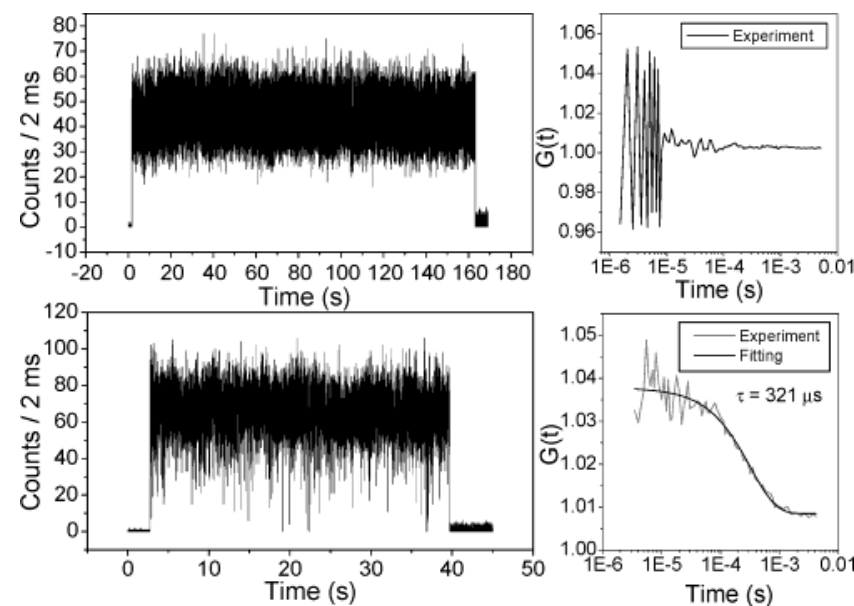

Figure 7. Transients (right) and autocorrelation functions (left) for two compound 1 molecules. The one in the upper panel does not show any decay time in the autocorrelation function. The one in the lower panel shows an autocorrelation decay time of $321 \mu \mathrm{s}$.

molecule experiments are attributed to the triplet formation. ${ }^{60}$ We estimated the triplet lifetime of compound 1 from continuous wavelength excitation measurements using the autocorrelation curves computed for the macrotime traces with a time resolution of $0.5 \mu \mathrm{s}$. The analysis was based on 178 molecules. Almost half of the molecules (45\%) showed no detectable autocorrelation time of the transient. For the rest of the molecules, the histogram plotted for the decay times of the autocorrelation curves give an average lifetime for the triplet state of $290 \mu \mathrm{s}$. The existence of these two subpopulations of molecules (Figure 7) is probably due to the heterogeneity of the PVA matrix. The molecules trapped in the water pockets of the polymer show no autocorrelation because the triplet lifetime is at the detection
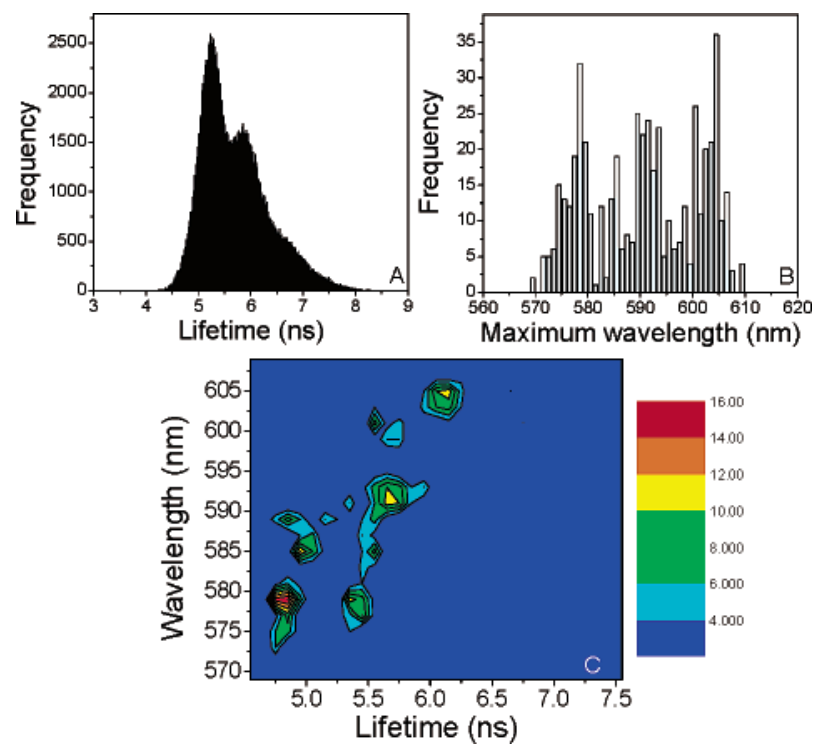

Figure 8. Histograms of fluorescence decay times (A) and maximum emission wavelengths (B) for single molecules of compound 1 in PVA matrix. (C) Correlation between single molecule lifetimes and maximum emission wavelengths.

limit (1.5-2 $\mu$ s as determined by FCS) and the contribution of the triplet is very low. Molecules that reside in the polymer have a triplet lifetime around $300 \mu$ s, longer than in solution and detectable because of the reduced solubility and permeability for oxygen of the polymer. The yield of the intersystem crossing $\left(\Phi_{\mathrm{T}}\right)$ and the intersystem crossing rate constant $\left(k_{\mathrm{ISC}}\right)$ were calculated from the autocorrelation curves, ${ }^{68}$ and the average values for compound 1 molecules are $\Phi_{\mathrm{T}}=1.8 \times 10^{-4}$ and $k_{\mathrm{ISC}}=3.6 \times 10^{4} \mathrm{~s}^{-1}$.

Comparing the intersystem crossing rate calculated for compound 1 with values determined in the literature in similar conditions and by the same method, ${ }^{68}$ one can observe that $k_{\mathrm{ISC}}$ for the water-soluble PDI $\left(k_{\mathrm{ISC}}=3.6 \times 10^{4} \mathrm{~s}^{-1}\right)$ is 2 orders of magnitude lower than for the rhodamine derivative JF9 $\left(k_{\mathrm{ISC}}=\right.$ $\left.1.5 \times 10^{6} \mathrm{~s}^{-1}\right)$ and for Cy5 $\left(k_{\mathrm{ISC}}=1 \times 10^{6} \mathrm{~s}^{-1}\right)$. This can contribute to the decreased photobleaching of the molecule.

c. Other Parameters. The histogram plotted using the values for the decay times determined along all the transients (Figure 8A) shows three distributions: around 5, 6, and 6.3 ns. The standard error $\sigma$ for the lifetime determination at single molecule level in our experimental conditions was calculated to be 0.2 ns. ${ }^{48}$ The histogram computed with maximum wavelengths determined for all recorded spectra of compound 1 molecules shows also three distributions: $575-580 \mathrm{~nm}, 590-595 \mathrm{~nm}$, and 600-605 nm (Figure 8B). Because three distributions appear in the histogram of lifetimes, as well as in the histogram of maximum wavelengths, we tried to see if a correlation is possible. Indeed, it seems that shorter lifetimes correlate with maxima situated at slightly higher energies, and longer lifetimes with spectral maxima red shifted (Figure 8C).

On one hand, the distributions can reflect the heterogeneity of the polymer matrix sites sensed by the different chromophores. On the other hand, as demonstrated by molecular calculations (Spartan, Wave Function Inc.), substitutions in the bay positions lead to a twisted conformation of the core. The degree of twisting was associated with modifications in lifetime and spectral characteristics. ${ }^{49}$ In the water-soluble PDI, the three different populations of lifetimes and maximum emission wavelengths are probably the result of different degrees of twisting of the molecules combined with the effect of different environments existing inside the polymer film. 

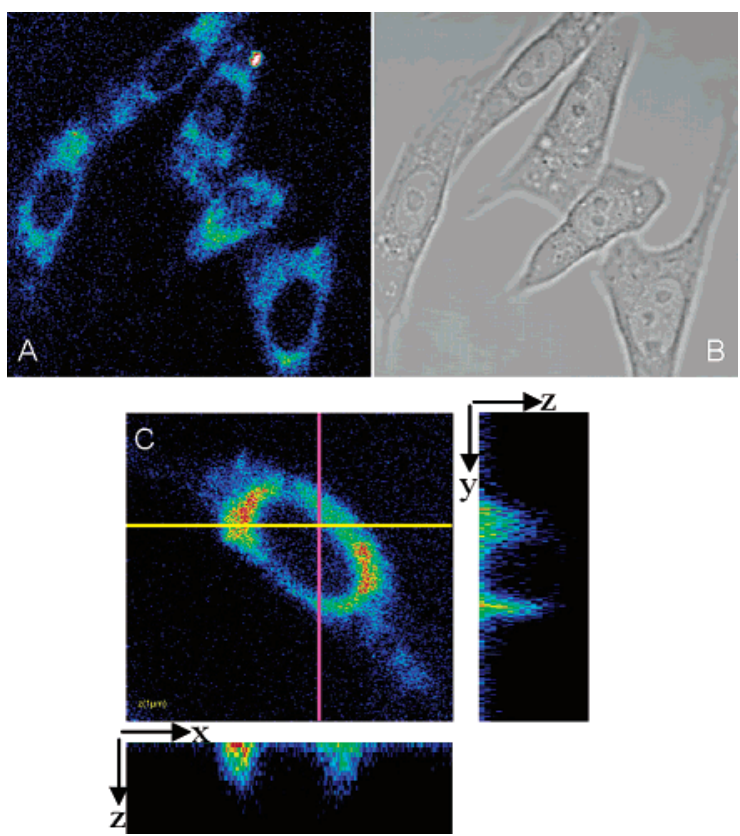

Figure 9. Fluorescence (A) and transmission (B) images of $\mathrm{CHO}$ cells loaded for $2 \mathrm{~h}$ with $5 \mu \mathrm{M}$ compound 1. (C) Fluorescence intensities reconstituted on the $z$ direction for two lines selected through a cell from an $x y z$-scanning. Both fluorescence images clearly show the presence of the dye in the intracellular compartments surrounding the nucleus but not inside the nucleus.

Measurements in Cells. A. One-Photon Excitation. To test the feasibility of using this molecule for measurements in living cells, the dye incorporation into cells was investigated. Interaction with cellular membranes seems not to be very favorable, because after $1 \mathrm{~h}$ of incubation with a buffer solution containing $5 \times 10^{-6} \mathrm{M}$ compound 1 , no fluorescence could be detected with the dye attached to the plasma membrane being probably washed (data not shown). The dye can be detected predominantly in the intracellular compartments except for the nucleus only after $2 \mathrm{~h}$ of loading, as demonstrated by confocal microscopy images (Figure 9).

B. Two-Photon Excitation. Nonlinear excitation of fluorophores is intensively used in recent years in microscopy techniques for biological applications because of several advantages. ${ }^{55,54}$ The excitation and fluorescence emission are confined to the focal point because of the squared power dependence of the absorption with the light intensity. Excitation wavelengths are shifted to the near-infrared region, avoiding limitations of UV lasers and optics, and providing a deep penetration necessary to imagine thick biological specimens. There is no background, because Rayleigh and Raman scattering occur at much longer wavelength than the collected fluorescence, and the out-of-plane excitation of chromophores is not possible. Also, out-of-focus photobleaching is eliminated. Combining the advantages of infrared pulsed lasers with a detector capable of fast gating, fluorescence lifetime can be mapped spatially in a technique called fluorescence lifetime imaging microscopy (FLIM). The feasibility of using compound 1 for two-photon application is demonstrated by lifetime images that we obtained in living cells with 850-nm excitation (Figure 10B). The contrast in the FLIM image obtained in living cells comes from the different lifetimes of the fluorophore, which are dependent on the particular environment of subcellular structures or on the presence of quenchers, but not on the fluorescence intensity, local probe concentration (within certain limits), or photobleaching. ${ }^{70,71}$ The intensity values (Figure 10A) for each pixel
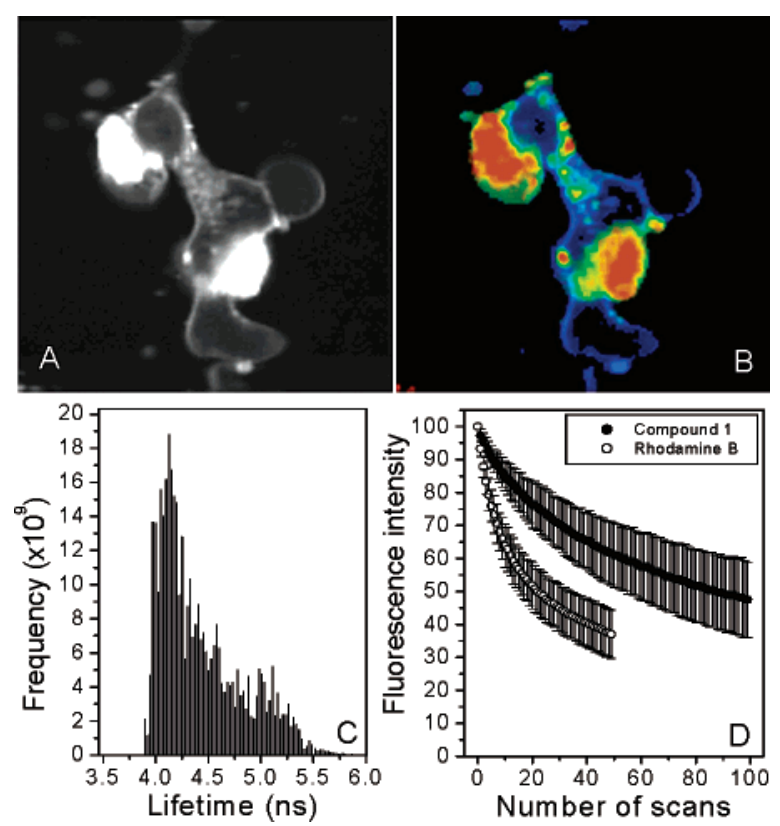

Figure 10. Two-photon intensity (A) and lifetime (B) images of HEK293 cells loaded for $4 \mathrm{~h}$ with $1 \mu \mathrm{M}$ compound 1 . The red color corresponds to lifetimes around $4 \mathrm{~ns}$, and the blue color to lifetimes longer than $5 \mathrm{~ns}$. (C) The distribution of lifetimes detected in panel B. (D) Two-photon photobleaching of compound 1 and rhodamine B. Compound 1 was loaded into cells for $2 \mathrm{~h}(5 \mu \mathrm{M})$ and rhodamine $\mathrm{B}$ for $1 \mathrm{~h}(1 \mu \mathrm{M})$. Each point on the two curves is the average of 10 photobleached regions in living cells. Fluorescence intensity was normalized to the first image in the sequence.

acquired for a certain time (usually a few minutes) can be fitted with an exponential (or multiexponential) function, resulting in the lifetime image (Figure 10B).$^{72}$ Because the mechanism of the water-soluble PDI incorporation into living cells is still under investigation, the distribution of lifetimes (Figure 10C) is not discussed. The fact that lifetimes shorter than in solution are detected in cells could be attributed to some quenching processes occurring either if the dye is associated to mitochondria (because of the electron-transfer process related to the oxidative phosphorylation) or if the dye is trapped in endolysosomes (because of the presence of oxygen peroxides).

The stability in living cells of compound 1 was compared to that of rhodamine B in two-photon excitation experiments. HEK239 cells were loaded for $2 \mathrm{~h}$ with $5 \mu \mathrm{M}$ compound 1 or with $1 \mu \mathrm{M}$ rhodamine $\mathrm{B}$ for $1 \mathrm{~h}$. Regions in cells $(\approx 20 \times 10$ or $20 \times 20 \mu \mathrm{m}$ ) where the fluorophores accumulated were scanned repeatedly with the same excitation power for both dyes. Figure $10 \mathrm{D}$ presents the photobleaching results. Each point is an average of 10 photobleached regions. Fluorescence intensity was calculated in percentages compared to the intensity of the first image in the sequence. Because the time interval between two consecutive scans depends on the area of the regions that were chosen, the $x$-axis is represented in number of scans. The results show that also in these conditions the photobleaching of compound 1 takes place after a higher number of scans (i.e., a longer time) than for rhodamine B.

\section{Conclusions}

We presented in this paper a new fluorescent molecule with a high quantum yield in water and an improved stability to photobleaching that can represent a viable alternative to the other water-soluble dyes used in biology and can be successfully applied for single molecule studies, as well as for two-photon experiments. Important advantages that can impose this molecule 
are related to its low intersystem crossing rate leading to long observation times and high number of counts in FCS measurements. An interesting feature is that the molecule can be excited with wavelengths corresponding to $S_{0}-S_{1}$ and $S_{0}-S_{2}$ transitions. The latter can be easily reached in two-photon excitation with the commercially available Ti:sapphire lasers. The compound 1 molecules can also be applied for fluorescence energy transfer experiments in living cells especially as donors (e.g., to a terrylene diimide chromophore), otherwise an UV-excited fluorescence donor has to be used because of the presence of the $\mathrm{S}_{0}-\mathrm{S}_{2}$ absorption peak around $450 \mathrm{~nm}$. Furthermore, the low probability of triplet formation means that compound 1 molecules can be used to follow the dynamics of the fluorescence energy transfer even on fast time scales.

Acknowledgment. We thank Prof. Jozef Van Damme and Dr. Sophie Struyf from Department of Microbiology and Immunology at KU Leuven for providing the cells in culture. A. M. gratefully acknowledges the Research Foundation of KU Leuven through GOA 2001/2 and A. S. acknowledges a Max Planck Research Award received by the laboratory. S. H. thanks the JSPS for a postdoctoral fellowship. The FWO and Federal Science Policy through IAP/5/03 are thanked for financial support to the laboratory. The German Federal Ministry of Technology and the German Science Foundation are also acknowledged for research funding.

\section{References and Notes}

(1) Weiss, S. Science 1999, 283, 1676-1683.

(2) Schwille, P.; Haupts, U.; Maiti, S.; Webb, W. W. Biophys. J. 1999, 77, 2251-2265 182.

(3) Schwille, P.; Korlach, J.; Webb, W. W. Cytometry 1999, 36, 176-

(4) Rigler, R.; Pramanik, A.; Jonasson, P.; Kratz, G.; Jansson, O. T.; Nygren, P.-A.; Ståhl, S.; Ekberg, K.; Johansson, B.-L.; Uhlén, S.; Uhlén, M.; Jörnvall, H.; Wahren, J. Proc. Natl. Acad. Sci. U.S.A. 1999, 96, $13318-$ 13323.

(5) Zhong, Z.-H.; Pramanik, A.; Ekberg, K.; Jansson, O. T.; Jörnvall, H.; Wahren, J.; Rigler, R. Diabetologia 2001, 44, 1184-1188.

(6) Eggeling, C.; Fries, J. R.; Brand, L.; Günther, R.; Seidel, C. A. M. Proc. Natl. Acad. Sci. U.S.A. 1998, 95, 1556-1561.

(7) Schütz, G. J.; Kada, G.; Pastushenko, V. P.; Schindler, H. EMBO J. 2000, 19, 892-901.

(8) Harms, G. S.; Cognet, L.; Lommerse, P. H. M.; Blab, G. A.; Kahr, H.; Gamsjäger, R.; Spaink, H. P.; Soldatov, N. M.; Romanin, C.; Schmidt, T. Biophys. J. 2001, 81, 2639-2646.

(9) Lommerse, P. H. M.; Blab, G. A.; Cognet, L.; Harms, G. S.; SnaarJagalska, B. E.; Spaink, H. P.; Schmidt, T. Biophys. J. 2004, 86, 609-616.

(10) Tsien, R. Y. Аппи. Rev. Biochem. 1998, 67, 509-544.

(11) Miyawaki, A.; Llopis, J.; Heim, R.; McCaffery, J. M.; Adams, J. A.; Ikura, M.; Tsien, R. Y. Nature 1997, 388, 882-887.

(12) Matz, M. V.; Fradkov, A. F.; Labas, Y. A.; Savitsky, A. P.; Zaraisky, A. G.; Markelov, M. L.; Lukyanov, S. A. Nat. Biotechnol. 1999, 17, 969-973

(13) Niwa, H.; Inouye, S.; Hirano, T.; Matsuno, T.; Kojima, S.; Kubota, M.; Ohashi, M.; Tsuji, F. I. Proc. Natl. Acad. Sci. U.S.A. 1996, 93, 1361713622.

(14) Habuchi, S.; Cotlet, M.; Hofkens, J.; Dirix, G.; Michiels, J.; Vanderleyden, J.; Subramaniam, V.; De Schryver, F. C. Biophys. J. 2002 $83,3499-3506$.

(15) Griffin, B. A.; Adams, S. R.; Tsien, R. Y. Science 1998, 281, 269272.

(16) Adams, S. R.; Campbell, R. E.; Gross, L. A.; Martin, B. R.; Walkup, G. K.; Yao, Y.; Llopis, J.; Tsien, R. Y. J. Am. Chem. Soc. 2002, 124, $6063-$ 6076.

(17) Chattoraj, M.; King, B. A.; Bublitz, G. U.; Boxer, S. G. Proc. Natl. Acad. Sci. U.S.A. 1996, 93, 8362-8367.

(18) Cotlet, M.; Hofkens, J.; Maus, M.; Gensch, T.; Van der Auweraer, M.; Michiels, J.; Dirix, G.; Van Guyse, M.; Vanderleyden, J.; Visser, A. J. W. G.; De Schryver, F. C. J. Phys. Chem. B 2001, 105, 4999-5006.

(19) Cotlet, M.; Hofkens, J.; Köhn, F.; Michiels, J.; Dirix, G.; Van Guyse, M.; Vanderleyden, J.; De Schryver, F. C. Chem. Phys. Lett. 2001, $336,415-423$.

(20) Moerner, W. E. J. Chem. Phys. 2002, 117, 10925-10937.
(21) Larson, D. R.; Zipfel, W. R.; Williams, R. M.; Clark, S. W. Bruchez, M. P.; Wise, F. W.; Webb, W. W. Science 2003, 300, 14341436.

(22) Chan, W. C. W.; Maxwell, D. J.; Gao, X.; Bailey, R. E.; Han, M.; Nie, S. Curr. Opin. Biotechnol. 2002, 13, 40-46.

(23) Dubertret, B.; Skourides, P.; Norris, D. J.; Noireaux, V.; Brivanlou,

A. H.; Libchaber, A. Science 2002, 298, 1759-1762.

(24) Chan, W. C. W.; Nie, S. Science 1998, 281, 2016-2018.

(25) Murray, C. B.; Kagan, C. R.; Bawendi, M. G. Annu. Rev. Mater. Sci. 2000, 30, 545-610.

(26) Bailey, R. E.; Nie, S. J. Am. Chem. Soc. 2003, 125, 71007106.

(27) Esfand, R.; Tomalia, D. A. Drug Discov. Today 2001, 6, 427436.

(28) Shchepinov, M. S.; Udalova, I. A.; Bridgman, A. J.; Southern, E. M. Nucleic Acids Res. 1997, 25, 4447-4454.

(29) Shah, D. S.; Sakthivel, T.; Toth, I.; Florence, A. T.; Wilderspin, A. F. Int. J. Pharm. 2000, 208, 41-48.

(30) Maksimenko, A. V.; Mandrouguine, V.; Gottikh, M. B.; Bertrand, J.-R.; Majoral, J.-P.; Malvy C. J. Gene Med. 2003, 5, 61-71.;

(31) Quintana, A.; Raczka, E.; Piehler, L.; Lee, I.; Myc, A.; Majoros, I.; Patri, A. K.; Thomas, T.; Mule, J.; Baker, J. R., Jr. Pharm. Res. 2002 19, 1310-1316

(32) Padilla De Jesus, O. L.; Ihre, H. R.; Gagne, L.; Frechet, J. M. Szoka, F. C., Jr. Bioconjugate Chem. 2002, 13, 453-461

(33) Konda, S. D.; Wang, S.; Brechbiel, M.; Wiener, E. C. Invest. Radiol. 2002, 37, 199-204.

(34) Minard-Basquin, C.; Weil, T.; Hohner, A.; Rädler, J. O.; Müllen, K. J. Am. Chem. Soc. 2003, 125, 5832-5838.

(35) Finikova, O.; Galkin, A.; Rozhkov, V.; Cordero, M.; Hägerhäll, C.; Vinogradov, S. J. Am. Chem. Soc. 2003, 125, 4882-4893.

(36) Werts, M. H. V.; Verhoeven, J. W.; Hofstraat, J. W. J. Chem. Soc. Perkin Trans. 2000, 2, 433-439.

(37) Werts, M. H. V.; Woudenberg, R. H.; Emmerink, P. G.; van Gassel, R.; Hofstraat, J. W.; Verhoeven, J. W. Angew. Chem., Int. Ed. 2000, 39, $4542-4544$

(38) Gao, J.; Strässler, C.; Tahmassebi, D.; Kool, E. T. J. Am. Chem Soc. 2002, 124, 11590-11591.

(39) Hofkens, J.; Latterini, L.; De Belder, G.; Gensch, T.; Maus, M.; Vosch, T.; Karni, Y.; Schweitzer, G.; De Schryver, F. C.; Hermann, A.; Müllen, K. Chem. Phys. Lett. 1999, 304, 1-9.

(40) Gronheid, R.; Hofkens, J.; Köhn, F.; Weil, T.; Reuther, E.; Müllen, K.; De Schryver, F. C. J. Am. Chem. Soc. 2002, 124, 2418-2419.

(41) Qu, J.; Kohl, C.; Pottek, M.; Müllen, K. Angew. Chem., Int. Ed. 2004, 43, 1528-1531.

(42) Lakowitz, J. R. Principles of Fluorescence Spectroscopy; Plenum Press: New York, 1986.

(43) Huang, S.; Heikal, A. A.; Webb, W. W. Biophys. J. 2002, 82, $2811-2825$

(44) Maus, M.; Rousseau, E.; Cotlet, M.; Schweitzer, G.; Hofkens, J.; Van der Auweraer, M.; De Schryver, F. C. Rev. Sci. Instrum. 2001, 72, $36-40$

(45) Cotlet, M.; Hofkens, J.; Habuchi, S.; Dirix, G.; Van Guyse, M.; Michiels, J.; Vanderleyden, J.; De Schryver, F. C. Proc. Natl. Acad. Sci. U.S.A. 2001, 98, 14398-14403.

(46) Schwille, P.; Kummer, S.; Heikal, A. A.; Moerner, W. E.; Webb, W. W. Proc. Natl. Acad. Sci. U.S.A. 2000, 97, 151-156.

(47) Cotlet, M.; Hofkens, J.; Maus, M.; De Schryver, F. C. In Fluorescence Spectroscopy, Imaging and Probes: New Tools in Chemical, Physical and Life Sciences; Kraayenhof, R., Visser, A. J. W. G., Gerritsen, H. C., Eds.; Springer-Verlag: Heidelberg, Germany, 2002; p 131-150.

(48) Maus, M.; Cotlet, M.; Hofkens, J.; Gensch, T.; De Schryver, F. C. Anal. Chem. 2001, 73, 2078-2086.

(49) Hofkens, J.; Vosch, T.; Maus, M.; Köhn, F.; Cotlet, M.; Weil, T.; Herrmann, A.; Müllen, K.; De Schryver, F. C. Chem. Phys. Lett. 2001, $333,255-263$.

(50) Liu, D.; De Feyter, S.; Cotlet, M.; Stefan, A.; Wiesler, U.-M.; Herrmann, A.; Grebel-Koehler, D.; Qu J.; Müllen, K.; De Schryver, F. C. Macromolecules 2003, 36, 5918-5925.

(51) Gvishi, R.; Reisfeld, R.; Burshtein, Z. Chem. Phys. Lett. 1993, 213 , $338-344$

(52) Ha, T. Methods 2001, 25, 78-86.

(53) Bindhu, C. V.; Harilal, S. S. Anal. Sci. 2001, 17, 141-144.

(54) Zipfel, W. R.; Williams, R. M.; Webb, W. W. Nat. Biotechnol. 2003, 21, 1369-1377.

(55) Xu, C.; Zipfel, W.; Shear, J. B.; Williams, R. M.; Webb, W. W. Proc. Natl. Acad. Sci. U.S.A. 1996, 93, 10763-10768.

(56) Korlach, J.; Schwille, P.; Webb, W. W.; Feigenson, G. W. Proc Natl. Acad. Sci. U.S.A. 1999, 96, 8461-8466. 
(57) Eggeling, C.; Widengren, J.; Rigler, R.; Seidel, C. A. M. Anal. Chem. 1998, 70, 2651-2659.

(58) Radford, S. E. Trends Biochem. Sci. 2000, 25, 611-618.

(59) Hohng, S.; Wilson, T. J.; Tan, E.; Clegg, R. M.; Lilley, D. M. J.; Ha, T. J. Mol. Biol. 2004, 336, 69-79.

(60) Xie, X. S.; Trautman, J. K. Аnnu. Rev. Phys. Chem. 1998, 49, 441480.

(61) Chirico, G.; Cannone, F.; Baldini, G.; Diaspro, A. Biophys. J. 2003, $84,588-598$.

(62) Deschenes, L. A.; Vanden Bout, D. A. Chem. Phys. Lett. 2002 $365,387-395$.

(63) Garcia-Parajo, M. F.; Segers-Nolten, G. M. J.; Veerman, J.-A.; Greve J.; van Hulst, N. F. Proc. Natl. Acad. Sci. U.S.A. 2000, 97, 72377242.

(64) Mei, E.; Tang, J.; Vanderkooi, J. M.; Hochstrasser, R. M. J. Am. Chem. Soc. 2003, 125, 2730-2735.
(65) Hernando, J.; van der Schaaf, M.; van Dijk, E. M. H. P.; Sauer M.; García-Parajó, M. F.; van Hulst, N. F. J. Phys. Chem. A 2003, 107 $43-52$.

(66) Hou, Y.; Higgins, D. A. J. Phys. Chem. B 2002, 106, 1030610315.

(67) Zondervan, R.; Kulzer, F.; Kol'chenko, M. A.; Orrit, M. J. Phys. Chem. A 2004, 108, 1657-1665.

(68) Tinnefeld, P.; Herten, D.-P.; Sauer, M. J. Phys. Chem. A 2001, $105,7989-8003$.

(69) Lounis, B.; Deich, J.; Rosell, F. I.; Boxer, S. G.; Moerner, W. E. J. Phys. Chem. B 2001, 105, 5048-5054.

(70) Tadrous, P. J. J. Pathol. 2000, 191, 229-234.

(71) Bastiaens, P. I. H.; Squire, A. Trends Cell Biol. 1999, 9, 48-51.

(72) Kaneko, H.; Putzier, I.; Frings, S.; Gensch, T. Curr. Top. Membr. 2002, 53, 163-189. 